\title{
Machado de Assis leitor dos românticos brasileiros
}

\section{Andréa Sirihal Werkema}

\begin{abstract}
Resumo: $\mathrm{O}$ artigo busca reler os textos críticos em que Machado de Assis contempla alguns dos autores românticos brasileiros, de forma a averiguar a sua assimilação dos procedimentos textuais do movimento que marcou o nascimento de nossa identidade literária. Por outro lado, o trabalho busca surpreender, nesses textos, a formação e o estabelecimento de um olhar sobre o romantismo brasileiro - olhar que se perpetua em nossa crítica literária atual. Palavras-chave: Machado de Assis, crítica literária, romantismo brasileiro.
\end{abstract}

Abstract: The present text reads the critical essays that $M$. de Assis wrote about some of the Brazilian romantic authors, in order to recognize his apprehension of the textual proceedings of this movement, which distinguishes the birth of the Brazilian literary identity. On the other side, the article tries to expose, in Machado's critique, the development and the establishment of a theory of Brazilian Romanticism - a theory that perpetuates itself until today in our literary criticism. Keywords: Machado de Assis, literary criticism, Brazilian Romanticism. 
Em 1866, ao final de sua resenha crítica sobre Iracema, escreve Machado de Assis: “Tal é o livro do Sr. José de Alencar, fruto do estudo, e da meditação, escrito com sentimento e consciência". Tais linhas servem à perfeição como mote para o que se quer tratar neste texto - "estudo", "meditação", "sentimento" e "consciência" seriam as balizas da leitura crítica feita por Machado de Assis dos autores românticos brasileiros.

Peço licença, porém, para adiantar um pouco o relógio e ir a 1873 e 1879, anos de publicação, respectivamente, dos célebres ensaios "Notícia da atual literatura brasileira - Instinto de nacionalidade" e "A nova geração". Sim, porque nestes ensaios, escritos na década em que se findava o romantismo entre nós, podemos apreender com mais clareza o balanço que faz Machado do movimento de que foi contemporâneo e ao qual sobreviveu. Nas palavras de João Alexandre Barbosa:

[...] os dois ensaios machadianos se singularizam pelo modo como buscam, por um lado, ler o passado literário brasileiro, fixando um elemento de articulação que dá resistência teórica a suas observações de ordem histórica e, por outro, a acuidade propriamente literária, e até mesmo técnica, com que lê a poesia pós-romântica de seu momento, tal como era cultivada por jovens escritores. ${ }^{2}$

Em "Instinto de nacionalidade", a questão mais que central na literatura brasileira, ou seja, a da identificação de um índice diferenciador, recebe contribuição inegável na formulação de que "o que se deve exigir do escritor, antes de tudo, é certo sentimento íntimo, que o torne homem do seu tempo e do seu país, ainda quando trate de assuntos remotos no tempo e no espaço". ${ }^{3}$ A transformação do sentimento nacional em forma, no lugar de uma substância estanque, já foi apontada por Luiz Costa Lima, ${ }^{4}$ entre outros, e implica a aceitação de que ser nacional em literatura é algo que muda ao longo do tempo e que não se deixa apreender nas delimitações

1 ASSIS, Machado de. Iracema, por José de Alencar. In: Crítica literária. Rio de Janeiro, São Paulo, Porto Alegre: W. M. Jackson Inc., 1955, p. 83. Publicado originalmente no Diário do Rio de Janeiro no dia 23 de janeiro de 1866.

BARBOSA, João Alexandre. Literatura e história: aspectos da crítica de Machado de Assis. In: SECCHIN, Antonio Carlos et al. (Org.). Machado de Assis: uma revisão. Rio de Janeiro: In-Fólio, 1998, p. 215.

3 ASSIS, Machado de. Notícia da atual literatura brasileira - Instinto de nacionalidade. In: Crítica literária, p. 135. Publicado originalmente na Revista Novo Mundo em 1873.

4 Cf. LIMA, Luiz Costa. O controle do imaginário: razão e imaginação nos tempos modernos. Rio de Janeiro: Forense Universitária, 1989, p. 148. 
artificiais forjadas entre as escolas literárias: "Nesse sentido, um dos pontos mais altos da crítica machadiana são as considerações que ele faz sobre as relações do escritor com o momento, com a escola ou o estilo literário predominante, ao mesmo tempo que se colocam em evidência as ligações da obra de arte com a vida". ${ }^{5}$ Não se trata evidentemente de atrelar um escritor a um estilo literário; ao contrário, revelar os vínculos de um autor com o momento em que escreve dá a Machado uma visão refinada do alcance da obra em questão, de seus limites e de suas realizações. Mais do que isso, no entanto, o texto de Machado separa de forma radical a questão da nacionalidade em literatura da literatura propriamente dita: "Não há dúvida que uma literatura, sobretudo uma literatura nascente, deve principalmente alimentar-se dos assuntos que lhe oferece a sua região; mas não estabeleçamos doutrinas tão absolutas que a empobreçam". ${ }^{6}$ Ora, separar as duas instâncias revela um olhar muito particular sobre o movimento romântico brasileiro, que sabidamente pautou-se pela ancoragem em um projeto de fundação nacional. Ou não? Teria Machado de Assis enxergado em obras de alguns de nossos autores românticos outra opção de projeto literário para além do "senso de dever patriótico, que levava os escritores não apenas a cantar a sua terra, mas a considerar as suas obras como contribuição ao progresso"?7 Teria Machado de Assis um projeto próprio, crítico e literário, que recusava o "empobrecimento" decorrente de uma leitura unívoca da produção nacional? Tal suposição traria consigo a necessidade de redimensionar o tão decantado projeto romântico de criação da literatura nacional com vistas à reinserção da obra de Machado de Assis na literatura brasileira. Se isso não cabe neste tão rápido comentário, seria, no entanto, interessante guardar a noção de que o Machado crítico literário se sabe herdeiro de uma tradição crítica começada no romantismo brasileiro. O ensaio "Instinto de nacionalidade" atesta, já em 1873, a preocupação em revisar, sistematicamente, a contribuição e as ressonâncias do movimento romântico na formação da literatura brasileira. É por isso que Antonio Candido, em sua obra já clássica, lançará mão do texto machadiano para fechar suas considerações acerca do "processo por meio do qual os brasileiros tomaram consciência de sua existência

CASTELLO, José Aderaldo. Realidade e ilusão em Machado de Assis. São Paulo: Companhia Editora Nacional/ Edusp, 1969, p. 29

ASSIS, Machado de. Notícia da atual literatura brasileira - Instinto de nacionalidade, p. 135.

CANDIDO, Antonio. Formação da literatura brasileira, vol. 2. Belo Horizonte: Rio de Janeiro: Itatiaia, 1993, p. 12. 
espiritual e social através da literatura", pois o ensaio de Machado exprime "o ponto de maturidade da crítica romântica; a consciência real que o romantismo adquiriu do seu significado histórico". ${ }^{9}$ Anote-se, por enquanto, que este célebre ensaio não conclui nenhuma das discussões que incita: o "instinto de nacionalidade" aí caracterizado é uma "busca" ${ }^{10}$ permanente da literatura brasileira, e não um objetivo. O que nos leva de volta a uma visão móvel do mesmo "instinto", enquanto forma, "variável, reajustável com a posição do que fala, deixando de se confundir com um modo de ser constante, originado de raízes eternas", ${ }^{11}$ ainda nas palavras de Costa Lima. Para o exame da leitura machadiana dos autores românticos brasileiros, um deslocamento da questão nacionalista em literatura passa a ser precioso: faz-se possível o estabelecimento de uma linha evolutiva no pensamento crítico de Machado, a partir de seu interesse pelo romantismo.

Assim, também no ensaio de 1879, "A nova geração", Machado volta a olhar para o romantismo brasileiro como um movimento literário que finda, mas que vem a ser precursor do momento literário que o crítico analisa, e que lhe é contemporâneo. "A nova geração" é, por um lado, verdadeiro epitáfio do romantismo no Brasil ("o ocaso de um dia que verdadeiramente acabou" ${ }^{12}$ ), e lhe atesta, ao mesmo tempo, a vitalidade que é própria de todos os movimentos fundadores. Mais importante é falar de uma nova geração que se segue à geração anterior: está patente no ensaio de Machado a formação de uma série literária em âmbito brasileiro, assim como fica registrada a necessidade de uma crítica literária capaz de ler a série literária, apontando-lhe os equívocos de percurso e emprestando-lhe, pela força do olhar até certo ponto isento, uma forma mais coerente. Vislumbra-se em "A nova geração" o cruzamento de duas instâncias fundamentais para o surgimento da crítica literária: o estabelecimento de um critério estético para o julgamento das obras analisadas e o traçado de uma história da literatura (brasileira, no caso). Para isso Machado observa em primeiro lugar a relação dos poetas da nova geração com seus antecessores:

CANDIDO, Antonio. Formação da literatura brasileira, vol. 2. p. 327.

CANDIDO, Antonio. Formação da literatura brasileira, vol. 2. p. 327.

Cf. BAPTISTA, Abel Barros. A formação do nome - Duas interrogações sobre Machado de Assis. Campinas:

Editora da Unicamp, 2003, p. 50.

11

LIMA, Luiz Costa. O controle do imaginário: razão e imaginação nos tempos modernos, p. 148.

ASSIS, Machado de. A nova geração. In: Crítica literária, p. 180. Publicado originalmente na Revista Brasileira, vol. II, no dia $1^{\circ}$ de dezembro de 1879 .

Teresa revista de Literatura Brasileira [12|13]; São Paulo, p. 496-507, 2013 • 499 
A nova geração chasqueia às vezes do romantismo. Não se pode exigir da extrema juventude a exata ponderação das coisas; não há impor a reflexão ao entusiasmo. De outra sorte, essa geração teria advertido que a extinção de um grande movimento literário não importa a condenação formal e absoluta de tudo o que ele afirmou; alguma coisa entra e fica no pecúlio do espírito humano. Mais do que ninguém, estava ela obrigada a não ver no romantismo um simples interregno, um brilhante pesadelo, um efeito sem causa, mas alguma coisa mais que, se não deu tudo o que prometia, deixa quanto basta para legitimá-lo. Morre porque é mortal. ${ }^{13}$

Eu dissera que Machado observa a nova geração, mas na verdade surpreende-se no trecho citado, e de forma clara, a opinião do crítico acerca da importância que o movimento romântico teria de, forçosamente, adquirir aos olhos dos novos poetas, fossem eles leitores mais atentos de suas próprias obras. É Machado de Assis quem vê, enquanto leitor consciente de uma história literária, a posição fulcral do romantismo na literatura brasileira. E aponta para a instituição de uma série literária: não há "extinção" absoluta de um movimento literário, há antes a formação de um "pecúlio" estético pela sobreposição dos diferentes momentos de uma série literária. Essa sobreposição não se faz automaticamente, pelo mero acúmulo, antes necessita do olhar crítico, que escolhe, que compara, que estabelece a "continuidade crítica" ${ }^{14}$ entre as escolas literárias. A noção de precursor não prevê, de forma alguma, a passividade em sua aceitação: o romantismo, visto em "A nova geração" como precursor possível da poesia contemporânea a Machado de Assis, encerra-se devendo ser analisado em suas contribuições, deficiências e, ao mesmo tempo, mortalidade e persistência.

Voltando finalmente à década de 1860, é possível encontrar, no entanto, já no ensaio "O ideal do crítico", de 1865, formulações que apontam na mesma direção. Nesse texto, Machado identificava na abertura para as diferentes escolas literárias uma característica fundamental da atividade crítica, o que podemos interpretar como admirável capacidade historicista de leitura do jovem autor. Em suas palavras:

É preciso que o crítico seja tolerante, mesmo no terreno das diferenças de escola: se as preferências do crítico são pela escola romântica, cumpre não condenar, só por isso, 
as obras-primas que a tradição clássica nos legou, nem as obras meditadas que a musa moderna inspira; do mesmo modo devem os clássicos fazer justiça às boas obras dos românticos e dos realistas, tão inteira justiça, como estes devem fazer às boas obras daqueles. ${ }^{15}$

Machado advoga em favor de uma leitura consciente de cada um dos autores responsáveis pelo molde dos diferentes estilos literários no Brasil. Assim sua reavaliação do movimento romântico, e dos ideais literários românticos, empreendida na tentativa de avaliação do momento contemporâneo, mostra em Machado o homem de seu tempo, momento de transição e de formação de uma continuidade crítica na literatura brasileira. Por isso os autores de nosso período colonial, em especial os neoclássicos ambiguamente percebidos pelos românticos, podem ser agora recolocados na série literária, livres das leituras anacrônicas que pediam a eles, de forma insensata, liberdade não só estética, como política. É no cerne mesmo da oposição marcada entre uma literatura colonial, presa a um código de convenções, e o romantismo pós-Independência que se torna interessante procurar o persistente traço comum, fabricado antes pelo olhar crítico do que pelo simples acúmulo cronológico.

Três textos críticos escritos por Machado de Assis em 1866 lidam com autores românticos brasileiros, estando, portanto, mais próximos de "O ideal do crítico" do que de "Instinto de nacionalidade" ou de "A nova geração" - e podem ser lidos também como preparação para a escrita destes ensaios mais maduros. "Instinto de nacionalidade" põe lenha na fogueira das discussões oitocentistas sobre nacionalidade em literatura; "A nova geração" mostra um crítico que já pode lançar os olhos em volta de si e comentar, a partir da perspectiva de fim de uma era literária, a nova literatura feita por seus contemporâneos. Interessa agora a passagem do olhar de Machado de Assis pelos escritores românticos via resenha crítica; se é certo que o aproveitamento de sua avaliação crítica do romantismo foi feito por Machado também em seus poemas, contos e romances (poderíamos aqui discutir longamente a chamada "virada romanesca" de 1880 a partir deste ponto de vista), tentarei ater-me, brevemente, às observações críticas do autor acerca de três livros românticos que ele analisa, ou seja, Iracema, Inspirações do claustro e Lira dos vinte anos. Tentemos ver aí, objetivada, a tendência crítica da obra machadiana. 
O texto sobre Iracema,${ }^{16}$ como já citado, saiu em 1866, logo no ano seguinte à publicação do livro, portanto, e é uma resenha crítica no sentido quase jornalístico da palavra, pois apresenta o livro a eventuais leitores, expondo defeitos e qualidades através da descrição de enredo, personagens e aspectos formais. Mas, para chegar a isto, Machado de Assis primeiro introduz a questão do indianismo na literatura brasileira, e de seus representantes e adversários. Faz-se assim o elogio de Gonçalves Dias, criador original de sentimentos e ideias literários, em oposição aos epígonos que utilizavam apenas o vocabulário indígena, praticando um indianismo superficial e imitativo. Nota-se que Machado procura discriminar, entre os vários autores que produziram obras indianistas, os criadores dos imitadores - e isso se faz pela leitura individualizada de cada autor, e não pela consideração do indianismo enquanto fenômeno da literatura brasileira ("Nem nos parece que se deva chamar escola ao movimento que atraiu as musas nacionais para o tesouro das tradições indígenas" ${ }^{17}$ ). Com isso, Machado procura afastar também o maior medo dos adversários do indianismo: a sua transformação em modo exclusivo de fazer literatura brasileira. Machado não tem dúvidas: para o verdadeiro criador, este era apenas mais um "dos modos de exercer a poesia nacional". ${ }^{18} \mathrm{O}$ indianismo, aos olhos de Machado, constitui-se em patrimônio da literatura brasileira, mas apenas na medida em que for trabalhado como dispositivo estético por nossos grandes autores; devem-se ignorar as limitações dos "maus rimadores", que ameaçam transformar o motivo indígena em massa amorfa, e obrigatória, de clichês e adereços exóticos.

Uma vez que se distinguem os bons dos maus poetas, e que se afasta a ameaça de uma literatura brasileira eternamente indianista, passa a ser possível analisar o romance de José de Alencar pela via do critério estético, à revelia de possíveis critérios extraliterários - processo crítico que será retrabalhado na metáfora do "sentimento íntimo", alguns anos depois. Iracema é, segundo Machado de Assis, "um poema em prosa”, fruto de trabalho minucioso de Alencar:

Estudando profundamente a língua e os costumes dos selvagens, obrigou-se o autor a entrar mais ao fundo da poesia americana; entendia ele, e entendia bem, que a poesia americana não estava completamente achada; que era preciso prevenir-se contra um anacronismo moral, que consiste em dar ideias modernas e civilizadas aos filhos incultos da floresta. [...] 
a verdade é que relemos atentamente o livro do Sr. José de Alencar, e o efeito que ele nos causa é exatamente o mesmo que o autor entende que se deve destinar ao poeta americano; tudo ali nos parece primitivo; a ingenuidade dos sentimentos, o pitoresco da linguagem, tudo, até a parte narrativa do livro, que nem parece obra de um poeta moderno, mas uma história de bardo indígena [...]. A conclusão a tirar daqui é que o autor houve-se nisto com uma ciência e uma consciência, para os quais todos os nossos louvores são poucos. ${ }^{19}$

A apreciação extremamente positiva do livro de Alencar mostra um crítico mais que atento ao trabalho do autor: pode-se acompanhar, no trecho citado, o percurso da leitura crítica - Machado parte das teses alencarinas expostas no posfácio "Carta ao Dr. Jaguaribe", ${ }^{20}$ que acompanha Iracema, coloca-as à prova na releitura minuciosa do romance e chega à conclusão de que as experiências formais que lhe constituem o cerne foram bem-sucedidas na medida em que, primeiro, alcançam um efeito no leitor análogo ao desejo autoral; segundo, expõem na matéria romanesca o trajeto reflexivo do autor, "ciência e consciência", motivos pelos quais os louvores do crítico são justos, na medida. Se Iracema é um momento complexo em nosso romantismo, alegra perceber que o romance teve um leitor à sua altura logo no primeiro momento; o que é aqui mais interessante, no entanto, é constatar que o uso sofisticado do arsenal indianista/brasileirista não encobriu o tour de force formal, produto da reflexão continuada sobre os meios da escrita. Parece-me bastante claro que uma virada crítica na avaliação da literatura brasileira, como a proposta por Machado de Assis em "Instinto de nacionalidade", tem suas raízes na leitura criteriosa de projetos literários consequentes como o de José de Alencar. Não é a utilização do motivo indígena que faz de Iracema o grande poema nacional ("modelo para o cultivo da poesia americana"21), mas os já citados estudo, meditação, sentimento e consciência que ressaltam em sua leitura ("para ele enviamos os leitores estudiosos"22).

O que nos leva, por fim, aos textos críticos que tratam de dois poetas do nosso chamado Ultrarromantismo, Junqueira Freire e Álvares de Azevedo. Avessos ao motivo indianista ou brasileirista, os dois jovens autores deixaram livros marcados por certo tom soturno que se costuma atribuir a circunstâncias biográficas, em indissociação tão ao gosto do romantismo subjetivista. Inspirações do claustro e Lira dos vinte

19 Idem, p. 75.

20 ALENCAR, José de. Carta ao Dr. Jaguaribe. In: Ficção completa (vol. II). Rio de Janeiro: Aguilar, 1964, p. 1122 a 1125.

21 ASSIS, Machado de. Iracema, por José de Alencar, p. 83.

22 Idem, p. 83. 
anos são analisados mais de dez anos depois de sua publicação, retirados da "estante nacional", nas palavras de Machado de Assis, à qual recorre na ausência de novas publicações literárias dignas de apreciação crítica.

O livro de Junqueira Freire, ${ }^{23}$ publicado em 1855 , impõe a Machado de Assis a distinção entre o poeta e sua obra - operação complexa em nosso âmbito romântico. As "circunstâncias romanescas, e legendárias" da vida do monge arrependido levam o crítico a ter de lidar com a sua transposição para a matéria literária: Machado elogia no livro a sinceridade com que o poeta recria, ou reescreve, a sua história íntima, "em versos, muitas vezes duros, mas geralmente saídos do coração". ${ }^{24}$ Ciente, até certo ponto, dos padrões estéticos românticos, Machado elogia a adequação da forma ao conteúdo - e volta a insistir nisto, dizendo que a beleza do livro está em um contraste, em contradições internas: é isto que "representa a consciência e a unidade do livro". ${ }^{25}$ O poeta e o monge habitam o livro; o livro é, portanto, ambíguo, tortuoso e original. Machado de Assis conclui:

O seu verso, porém, às vezes incorreto, às vezes duro, participa das circunstâncias em que nascia; traz em si o cunho das impressões que rodeavam o poeta [...]. Tivesse ele o cuidado de aperfeiçoar os seus versos, e o livro ficaria completo pelo lado da forma. O que lhe dá sobretudo um sabor especial é a sua grande originalidade, que deriva não só das circunstâncias pessoais do autor, mas também da feição própria do seu talento; Junqueira Freire não imita ninguém; rude embora, aquela poesia é propriamente dele; sente-se ali essa preciosa virtude que se chama - individualidade poética. ${ }^{26}$

Machado não evita os defeitos formais do livro, mas ressalta, acima deles, o maior dos valores românticos - a "individualidade poética" de Junqueira Freire é sua contribuição para a história da literatura brasileira, assim como a sua "grande originalidade". Esta deriva não apenas da dilacerada vivência do poeta: ela advém de suas particularidades criativas, do âmago de sua subjetividade marcada pela visão ultrarromântica de poesia. Ora, a incorreção e a dureza dos versos de Junqueira Freire estão perfeitamente de acordo com uma estética da irregularidade como apregoada pelos

Idem. Inspirações do claustro, por Junqueira Freire. In: Crítica literária, p. 84 a 94. Publicado originalmente no Diário do Rio de Janeiro no dia 30 de janeiro de 1866.

24 Idem. Inspirações do claustro, por Junqueira Freire, p. 85.

25 Idem, p. 87.

26 Idem, p. 93. 
mestres do momento - e, se Machado parece por vezes levar a sério demais a biografia conflituosa do frade, por outro lado procede de maneira bastante romântica ao procurar na própria obra os meios e instrumentos para a sua análise crítica. Daí que o valor da obra de Junqueira Freire se sobreponha aos seus descuidos formais - sua criticabilidade $^{27}$ liga-se antes à irregularidade programática e ao aproveitamento da biografia enquanto encenação de um "drama obscuro", ${ }^{28}$ matéria de poesia, do que a uma prática versificatória que almeje a perfeição formal.

Machado de Assis é, como se vê, o mesmo crítico que dizia, em 1865, ser fundamental a tolerância para com as diferenças de escola; e que dirá, em 1873, que o valor literário é algo de ordem interior, que faz do autor homem do seu tempo e do seu país. A originalidade de Junqueira Freire tem, portanto, ainda esse aspecto: é uma poesia "nova" - fala uma "língua própria" ${ }^{29}$-; o "não imitar ninguém" é também atestado de uma escrita cuja autonomia se comprova por sua originalidade no quadro da literatura brasileira, dentro da tradição ocidental.

Assim, também no curtíssimo texto sobre Lira dos vinte anos $^{30}$ busca Machado a índole do poeta por trás de seus escritos: a índole propriamente poética, a dicção da poesia de Álvares de Azevedo. Desde logo nota-se, diz Machado, a presença exagerada de outros autores em sua obra - o que ofusca muitas vezes a sua "individualidade poética”. Ao contrário de Junqueira Freire, cuja vida era em si assunto bastante de poesia, Álvares de Azevedo buscaria nos livros amados a experiência que lhe falta: "Ambicionava uma existência poética, inteiramente conforme à índole de seus poetas queridos". ${ }^{31}$ Livresca, defeituosa, artificiosa, a obra de Azevedo parece a Machado

27 O termo é usado aqui no sentido em que Benjamin lê o primeiro romantismo alemão: a obra romântica é aquela que contém dentro de si mesma, em germe, a sua possível leitura crítica, e que é, portanto, passível de ser criticada, na medida em que se torna objeto-centro de reflexão. Cf. BENJAMIN, Walter. $O$ conceito de crítica de arte no romantismo alemão. São Paulo: Iluminuras, 1999, p. 71 a 80.

28 "Nas doudas cenas de meu drama obscuro!", verso de Álvares de Azevedo, em seu belo poema "Ideias íntimas". In: AZEVEDO, Álvares de. Poesias completas. Campinas: Editora da Unicamp; São Paulo: Imprensa Oficial do Estado, 2002, p. 158.

29 ASSIS, Machado de. Inspirações do claustro, por Junqueira Freire, p. 93.

30 Idem. Lira dos vinte anos, poesias de Álvares de Azevedo. In: Crítica literária, p. 108 a 113. Publicado originalmente no Diário do Rio de Janeiro no dia 26 de junho de 1866.

31 Idem. Lira dos vinte anos, poesias de Álvares de Azevedo, p. 111. Conferir o pequeno ensaio em que Eugenio Gomes discorre sobre o "ópio da leitura", único vício do jovem poeta Álvares de Azevedo: GOMES, Eugenio. Álvares de Azevedo e o ópio da leitura. In: Leituras inglesas: visões comparatistas. Belo Horizonte: Ed. UFMG; Salvador: EDUFBA, 2000, p. 249 a 254.

Teresa revista de Literatura Brasileira [12|13]; São Paulo, p. 496-507, 2013 • 505 
de Assis, no entanto, dotada de grande talento e sensibilidade. O pressentimento da morte e a melancolia completam um quadro de compensação da vida pela poesia: Ultrarromantismo. Machado atribui à falta de tempo os exageros que embaçam a "individualidade" de Azevedo (esta expressão aparece quatro vezes em um texto de poucos parágrafos); o poeta, se tivesse vivido, teria definido melhor sua dicção poética, emendaria seus versos às vezes incorretos, desbastaria a sua prosa dos excessos advindos da erudição.

Quem lê o texto crítico de Machado de Assis sobre Álvares de Azevedo forma de imediato a ideia de um poeta ainda em desenvolvimento, incompleto, com a carreira que se anunciava brilhante abreviada pela morte. Ora, não deixa de ser interessante verificar que o que era aceitável em Junqueira Freire devido às circunstâncias biográficas, ou seja, seus maus versos, suas oscilações poéticas, só pode ser justificado em Azevedo pela falta de tempo (claro está que Lira dos vinte anos é livro póstumo, de 1853, ou seja, não passou pelo crivo do poeta na ocasião de sua publicação). Mas aquilo que o crítico condena com mais frequência em Azevedo assume certa relevância ao pensarmos no futuro escritor Machado de Assis - o excesso de leituras, a erudição descontrolada assenhoreando-se do texto: "Era frequentemente difuso e confuso; faltava-lhe precisão e concisão. Tinha os defeitos próprios das estreias, mesmo brilhantes como eram as dele. Procurava a abundância e caía no excesso. A ideia lutava-lhe com a pena, e a erudição dominava a reflexão". ${ }^{32}$ Um autor-leitor incomodado pelo excesso de leituras de outro autor-leitor. A formação de uma "individualidade poética" azevediana, nos termos quase obsessivos de Machado, necessitaria de mais tempo, mais reflexão, mais trabalho com a utilização de vozes alheias no próprio texto.

As reservas de Machado de Assis em relação à obra de Álvares de Azevedo me sugerem, sempre, um reconhecimento. Machado veria ali, em forma ainda incipiente, um modo de trabalhar as leituras na confecção de uma obra literária. Se efetivamente faltou tempo a Álvares de Azevedo, o poeta teria, no entanto, mesmo que de forma precária, indicado um caminho para a integração de toda uma tradição literária em sua própria obra. Tal questão assume ares graves no contexto da literatura brasileira, exposta desde sempre às discussões sobre fontes e influências, filiações e originalidade. Não custa lembrar que a leitura empreendida por Machado de Assis da "estante nacional" é formadora de toda uma visão crítica posterior sobre o romantismo brasileiro - aqui representado em sua chamada segunda fase por um poeta que evitou,

ASSIS, Machado de. Lira dos vinte anos, poesias de Álvares de Azevedo, p. 112. 
de maneira proposital, os temas mais óbvios da nacionalidade literária. Retomando os termos de Machado, Álvares de Azevedo teria buscado, através de sua inserção no quadro ocidental, outra forma possível de participação na literatura de seu tempo e de seu país. Essa "dialética do local e do universal" 33 será a marca do Machado de Assis maduro, que levará o procedimento ao seu alcance máximo, desenvolvendo-o a partir de suas próprias premissas, expostas em "Instinto de nacionalidade".

Cobrar do mais romântico de nossos autores "originalidade" e "individualidade" não pode deixar de ser sintomático: Machado exige de um talento que ele previa superior uma definição mais clara de projeto literário, no quadro possível da literatura romântica brasileira (por isso seu elogio ao humour, como contribuição nova de Azevedo à literatura brasileira). Estaríamos diante de um caso de reconhecimento de precursor? De formação de uma linhagem crítica de trabalho criativo com as leituras feitas pelo autor-leitor? São questões que exigiriam um trabalho longo e aprofundado - outro momento. Concluo às pressas o texto com o elogio final de Machado de Assis a Álvares de Azevedo; elogio que poderia tranquilamente ser feito ao autor de Brás Cubas:

Diz-nos ele que sonhava, para o teatro, uma reunião de Shakespeare, Calderón e Eurípides, como necessária à reforma do gosto da arte. Um consórcio de elementos diversos, revestindo a própria individualidade, tal era a expressão de seu talento. ${ }^{34}$

Andréa Sirihal Werkema é professora de Literatura Brasileira na UERJ, autora de Macário, ou do drama romântico em Álvares de Azevedo (Editora da UFMG, 2012). 